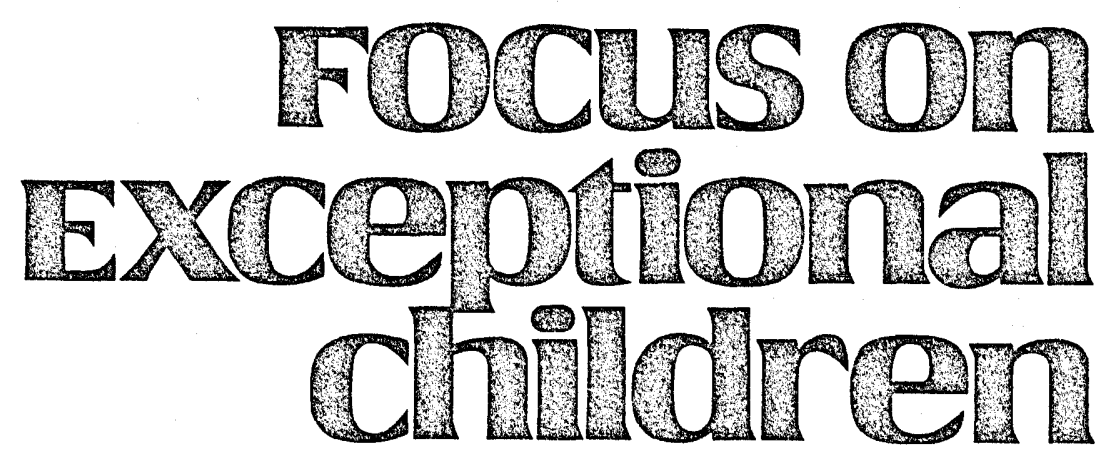

\title{
Potential Means of Enhancing Content Skills Acquisition in Learning Disabled Adolescents
}

\section{Bernice Y.L. Wong}

The current influence of cognitive psychology, especially of metacognitive theory and research, has generated a strategies approach in remediation of learning disabled (LD) students'academic problems (Wong, 1984). Thus, we read about self-monitoring strategies to focus LD children's attention (Loper, Hallahan, \& Ianna, 1982), monitoring of LD adolescents' reading comprehension (Wong \& Jones, 1982), selfinstruction st rategies as related to handwriting performance (Graham, 1983), teaching LD adolescents reciprocal questioning, summarization skills to improve students' reading comprehension (Palincsar, 1982), and a cognitive strategies approach in remediating LD adolescents' academic problems (Alley \& Deshler, 1979).

Although teaching LD students strategies is instructionally sound, LD researchers and practitioners apparently have overlooked the equally important aspect of LD students' content knowledge in the domain upon which the inculcated strategy is to be applied. This interaction between knowledge and strategy appears to have been overlooked by LD professionals.

The interdependence of knowledge (in a particular area) and strategy has been clearly shown by Chi (1981) and emphasized by Voss (1982). Chi showed that 7-yearold children with expert knowledge on dinosaurs categorized them according to more abstract than perceptual (physical) features. For example, the expert children categorized the dinosaurs into meat eaters versus plant eaters. The novice children categorized the dinosaurs according to their visual resemblance and similarities. The categorizing behaviors of the expert children resembled those of adults. Chi's findings suggested that the development of classification strategies interacts strongly with knowledge about the stimulus domain.

In another study, Chi (1981) further found that when a child's knowledge base is well established and stable (e.g., the child knows the names of her classmates well), she could learn to use a new strategy for retrieving the names. Prior to introduction of the new strategy, alphabetization (recalling classmates' names in alphabetical order), the child had used classroom seat arrangement as her retrieval strategy. When she had to learn a list of unfamiliar names (names that did not belong to friends), however, the same newly acquired strategy of alphabetization was not as facilitative in retrieving the names. These findings and others confirm the interdependence of knowledge and strategy use and indicate that the strategy approach in LD remediation requires revamping. 
Additional and important demonstration of the interactive role of knowledge and strategy generation is afforded by Miyake and Norman (1978). They clearly demonstrated that specific content knowledge was a determinant in students' generation of questions. Those investigators used two groups of college students. One group was ignorant of computers and text editors; the other group was given sufficient training in the use of a text editor. Specifically, the students were trained to use three commands of a text editor. The criterion in training was the students' editing one text unaided. Subsequently, both groups were instructed to learn to operate a different text editor by following either an easy, nontechnical manual or a difficult, technical manual. The students were further instructed to think out loud as they tackled the new text editor.

Miyake and Norman found an interesting interaction in their study: Novice students in computer science asked few questions on the difficult manual but more on the easy manual; the trained students showed the reverse pattern of questioning. Miyake and Norman interpreted the findings to suggest that to ask a question, one has to

\section{Focus on
Exceptional children}

FOCUS ON EXCEPTIONAL CHILDREN (ISSN0015-511X) (USPS 203-360) is published monthly except June, July, and August as a service to teachers, special educators, curriculum specialists, administrators, and those concerned with the special education of exceptional children. This journal is abstracted and indexed in Exceptional Child Education Resources, and is also available in microform from Xerox University Microfilm. Ann Arbor, Michigan. Subscription rates, $\$ 18.00$ per year. Copyright $\odot 1985$. Love Publishing Company. All rights reserved. Reproduction in whole or part without written permission is prohibited. Printed in the United States of America. Second class postage is paid at Denver, Colorado.

POSTMASTER: Send address changes to:

Love Publishing Company

Executive and Editorial Office

1777 South Bellaire Street

Denver, Colorado 80222

Telephone (303) 757-2579

EDITORIAL BOARD
Edward L. Meyen

University of Kansas
Glenn A. Vergason Georgia State University
Richard J. Whelan

University of Kansas Medical Center
Stanley F. Love

Publisher
Carolyn Acheson

Senior Editor have an optimal amount of prior or content knowledge in the particular subject matter at hand.

Clearly, the acquisition of knowledge, especially specific content knowledge, is important for all secondary students. This is because the secondary school curriculum demands thorough comprehension and sufficient retention of specific content knowledge in various subject areas. The acquisition of content knowledge for LD adolescents deserves particular attention because several factors mitigate against their knowledge acquisition. These include residual decoding problems, vocabulary deficiency, poor reading comprehension skills and instruction in content areas (e.g., social studies) lost because of time spent in remedial sessions in the resource room.

\section{THE FRAMEWORK FOR CONTENT ACQUISITION}

To address the concerns raised, the following framework is used as a basis for the discussion here. First, a division of content areas is made between content knowledge in social studies/geography and that in general science (e.g., physics). The basis for this division is the presumed differences in instructional goals in those content areas. Specifically, in social studies/geography in the secondary school, the instructional goal appears to be comprehension and retention of content knowledge. The instructional goal in general science at the secondary level, however, appears to be both acquisition and transfer (application) of content knowledge. Within each category of content knowledge, techniques that have been empirically shown to induce successful knowledge acquisition, or that have potential instructional implications for LD adolescents' content knowledge acquisition, will be discussed here.

\section{Social Studies/Geography}

The following techniques can lead to meaningful learning and retention of social studies curricula. They have been empirically substantiated, and then applied to LD adolescents.

\section{Hierarchical Summarization}

Taylor (1982) devised a summarization strategy to promote fifth graders' comprehension and retention of expository and social studies materials. Essentially, Taylor taught the students to generate main-idea statements for every heading, subheading, and paragraph in 
the given passage. Students first discussed the organization of the hierarchical summary they were to make after they were to skim a textual segment of three to four pages. The instructor emphasized to them the importance of following the organization of the text in their reading and studying. Subsequently, the students read the given passage silently, completed the summary independently, and studied what they had read by reviewing the summary.

Although Taylor's hierarchical summarization technique was used with elementary school children, Wongl used it with modification to increase the comprehension and retention of social studies curriculum in five LD adolescents. The modifications involved asking the students to verbalize how their summary statements of paragraphs subsumed by one particular sub-heading related to each other and to the sub-heading. Moreover, the LD adolescents were asked to review their completed hierarchical summaries with the goal of following the theme and sub-themes in the given passage(s).

There is, however, a caveat to the application of Taylor's technique with LD adolescents. Prior to being taught to use the hierarchical summarization technique, the LD adolescents must possess two prerequisite skills: (1) knowledge of the concept of a main idea, and (2) knowledge of and the ability to use summarization rules.

Aulls (1978) outlined a rules-approach in teaching students the concept of a main idea. The central idea is the students' recognition that the main-idea sentence is the one that clearly explains the general topic, and that all or most of the remaining sentences in the same paragraph elaborate on it and refer to it. In teaching LD students the concept of a main idea, the pilot study revealed that a final step/rule was necessary- - namely that students realize that the main-idea sentence holds the whole paragraph together. In deleting (or covering up) the main-idea sentence, the integrity or meaningfulness of the paragraph breaks down. Given this additional step, LD students learn the concept of the main idea quite readily.

Moreover, to supplement the training with a metacognitive component, LD students can be asked to selfcheck their identification of main-idea sentences in given paragraphs prior to their handing in the exercise, to see if deletion of these sentences does leave the paragraphs meaningless. This supplementary step reinforces the LD students' attention to and use of the additional rule/step in identifying a main-idea sentence.

The second prerequisite skill in LD adolescents' being able to learn Taylor's hierarchical summarization tech-

\footnotetext{
'B.Y.L. Wong utilized Taylor's technique in a pilot study on "Teaching Learning-Disabled Adolescents Hierarchical Summarization Skills" (unpublished).
}

nique is the students' ability to summarize given expository materials. This ability, in turn, refers to the students' knowledge of the underlying principles/rules in summarization. Brown and her associates have done much research on summarization (Brown \& Day, 1983; Brown, Campione, \& Day, 1981; Brown, Day, \& Jones, in press).

Based on the summarization model of Kintsch and van Dijk (1978) and informal analyses of.summarization protocols from children and adults, Brown and Day (1983) derived five basic rules of summarization: (1) deletion of unimportant information, (2) deletion of redundant information, (3) superordination (generalization) of lists (i.e., students are taught to use a category label for instances of a category; thus, arm, hand, neck, and foot can be subsumed by the categorical name of "body parts"), (4) selection of a topic sentence, and (5) invention or construction of a topic sentence when one is not forthcoming in the text. The ability to summarize text is crucial in critical reading and effective studying (Brown \& Day, 1983). Hare and Borchardt (1983) successfully taught underachieving adolescents the use of these summarization rules.

\section{Knowledge of Passage Structure}

Slater, Graves, and Piche (1984) found that teaching students to recognize passage structure and taking notes to highlight it substantially increased their retention of given expository materials. Specifically, these investigators taught students to recognize that passages can have organizational structures such as statement of a position with supportive information from succeeding paragraphs; listing of a number of causes and a number of effects with supporting information on each cause and effect; posing of a problem with solutions given from succeeding paragraphs; etc.

Slater et al. then devised a grid for students' notetaking. Having recognized the passage organizational structure (for example, one passage had a cause-andeffect organizational structure), the students were told that it contained one cause, three effects with supporting information, and nine related topics with supporting information. The students were instructed to locate the cause, record it in the grid, and to do the same with the effects, the supporting information, and the related topics with their supporting information. Figure 1 presents one possible outline format for such use. The number of Cause, Related Topic, Effect, and Support spaces should correspond to the number the teacher relates to the students. 
1. Cause:

Support:

Support:

Support:

Support:

2. Related Topic:

Support:

Support:

3. Effect:

Support:

Support:

Support:

$\overline{T a k e n ~ f r o m ~ S l a t e r, ~ G r a v e s, ~ \& ~ P i c h e ~(1984) ~}$

FIGURE 1

Sample Outline

The techniques of Taylor and Slater et al. achieve informational extraction through students' summarization and notetaking. Moreover, the permanence of the notes and their organization promote retention of content when the notes are reviewed.

Both Taylor's and Slater et al.'s techniques have been empirically validated for their effectiveness in increasing comprehension and retention of expository materials/ social studies content. With modifications that may be necessary to accommodate the instructional needs of $L D$ adolescents, use of those techniques may well increase their acquisition of content knowledge in social studies. Again, however, LD adolescents should possess the requisite prior knowledge of main-idea concept and adequate summarization skills before being taught to use the studying techniques of Taylor and Slater et al.

\section{Mapping}

Mapping is a procedure whereby textual relationships are extracted and represented through symbols. These symbols (e.g., A, B, C; =, , ;) and the relationships they portray in a simple diagram are purported to facilitate students' reading comprehension (Armbruster \& Anderson, 1980). In situations where specific relations occur amidst complex and awkward prose, the availability of this alternative representation of the same relationships conceivably can be helpful, particularly for LD adolescents.

In an exploratory study, Armbruster and Anderson (1980) reported using mapping to teach 11 eighth graders to understand six relationships found in given passages: examples, property, definitions, compare-contrast, temporal, and causal. The investigators wanted to see if mapping would increase adolescents'comprehension and free recall of passage content, and to discover what problems the students might experience in using mapping as a study aid. Figure 2 illustrates the various relationships represented through mapping.

Armbruster and Anderson found that mapping did increase the students' prose recall. The facilitative effects, however, were inconsistent across five passages. Clear facilitation was shown only in the students' recall on one passage. The reasons for the lack of statistically significant data are the small sample used (11 experimental subjects) and the additional factor of subjects' lack of motivation in participating in the study. These students saw no payoff in involvement since their performance in the study bore no relationship to their classroom grades. Moreover, the mapping procedure was quite taxing to learn. Nevertheless, in probability of recall of idea units mapped versus those not mapped in the passages, the experimental subjects did recall substantially more of idea units mapped.

Concerning problems that students encountered in using mapping, Armbruster and Anderson found that causal relationships were difficult to map, especially with longer units of text. The students also tended to forget to integrate all the relationships they had mapped from a passage. Further, they tended to show some kind of response set (i.e., fixating on mapping a particular relationship to the exclusion of others that occur in the same passage). But they did find the relationship of compare-contrast easy to discriminate in the given passages.

Clearly, the results of Armbruster and Anderson's exploratory study indicated that the facilitative effects of mapping as a promoter of reading comprehension and retention are tentative. More research is obviously in order. Nevertheless, realizing LD adolescents'difficulties in extracting meaning from their content texts, the mapping technique presents an attractive alternative because: (1) it cuts through the jungle of decoding, syntax, and difficult vocabulary and focuses on the relevant relations they should comprehend, (2) its symbols are easy to understand and do not strain their memory capacity, and (3) each relationship is accompanied by a list of key words that cue the students' recognition of the kind of relationship to be identified. The types of relationships mapped by Armbruster and Anderson occur frequently in social studies. Conceivably, mapping may prove useful as a study aid for LD adolescents in the content area of social studies.

Although the potential use of mapping for LD adolescents in social studies should be empirically substantiated, I think intelligent use of it in instruction need 
(1) $A$ is an instance of $B$.

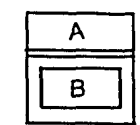

\begin{tabular}{|l}
\hline to \\
tor \\
typ \\
ex \\
exa \\
s \\
in
\end{tabular}

Example: A common type of setter is the Irish Setter

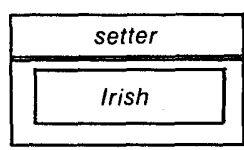

for example

for instance

type of

kind of

example of

e.g.

such as

include

including

(2) $A$ is a property of $B$.

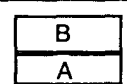

Example: Canaries are yellow

\begin{tabular}{|c|}
\hline canaries \\
\hline yellow \\
\hline
\end{tabular}

(to be)

(to have)

is a property of

$\begin{array}{ll}\text { is a feature of } & \text { is called } \\ \text { is a characteristic of } & \text { in other words }\end{array}$

is a part of

that is

\section{KEY WORDS}

the

(3) A defines (restates, clarifies) B.

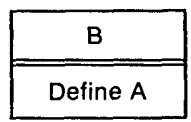

that is

in other words

i.e.

(to be)

is named

is called

is called

i.e.

is defined as

in other words

means that

\begin{tabular}{|c|}
\hline anthropology \\
\hline$D E F .=\begin{array}{c}\text { scientific study } \\
\text { of human culture }\end{array}$
\end{tabular}

(4) $A$ is similar to $B$. $\quad A \approx B$

Example: In most respects, Illinois and Ohio are very similar.

Illinois $\approx$ Ohio

like

likewise

is similar

similarly

in the same way

or manner (4a) $\quad A$ is not similar to $B . \quad A \not B$

Example: The soviet economic system is quite different from the American system.

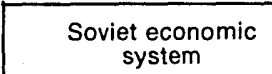
system
American economic system

(5) $A$ is greater than $B$

$$
A \geqslant B
$$

Example: $A$ liter is slightly more than a quart

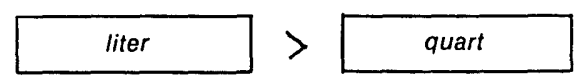

(6) A occurs before $B$. $\quad A \rightarrow B$

Example: Nixon resigned shortly before the Bicentennial celebration.

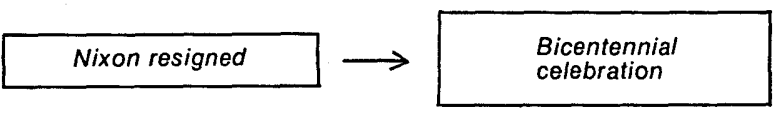

is different from 
FIGURE 2 (Continued)

(7) A causes $B$. $\quad A \Rightarrow B$

Example: Excessive exposure to the sun causes sunburn.

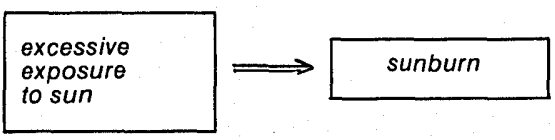

\begin{tabular}{|l|}
\hline \multicolumn{1}{|c|}{ KEY WORDS } \\
\hline causes \\
affects \\
leads to \\
in order to \\
produces \\
therefore \\
because \\
since \\
as a result of \\
this is because \\
consequently \\
\hline
\end{tabular}

From Armbruster and Anderson (1980). Only some of the symbolic relationships are shown for illustrative purposes.

not await the empirical stamp. For example, one can teach each of the six or more relationships consecutively, a new one being introduced upon a student's mastery of the previous one. Each LD adolescent should be given a prompt card listing the corresponding key (cue) words for the relationship being mapped from text. Similar to Armbruster and Anderson's procedure, one should provide opportunities for $\mathrm{LD}$ adolescents, in mapping, to voice aloud their thoughts and problems, and to inculcate metacognition - an awareness of why mapping may be helping their reading comprehension, learning, and retention of social studies content.

Armbruster and Anderson's mapping technique is a nonverbal means of representing relational information. Any secondary teacher intending to use it to promote LD adolescents' relational learning in social studies texts may find it appropriate for those students' particular instructional needs (i.e., the mapping procedure accommodates their decoding and vocabulary deficiencies and their deficient reading comprehension skills). Because social studies content contains many compare-contrast, definition, temporal relationships, the mapping procedure has a distinct instructional advantage. Users of this procedure, however, must remember to teach LD adolescents to criterion the use of key words that indicate to them what kind of relationship to map from the text. Moreover, teachers should provide LD adolescents a prompt listing these key words as they read through the social studies text in search of the various kinds of relationships they should map.

\section{Socratic Tutoring}

Socratic tutoring is an individualized teaching technique designed to inculcate reasoning skills in students. Specifically, the student is taught to derive general principles from specific cases, and to generalize these general principles to new cases (Collins, 1977).

Collins successfully used this method to teach students causal dependencies in geography. As he noted, the
Socratic tutoring teaching method originated with Plato but has cropped up in the inquiry method and is constantly used by good teachers to elicit relevant background knowledge and to focus students' attention on important factors, among other uses. In attempting to formalize a theory of Socratic tutoring, Collins extracted discernible strategies, involving the Socratic method, in pedagogic dialogues with students and formalized these strategies as "production rules." This formalization makes the theory of Socratic tutoring independent of particular content.

Moreover, Collins attempted to specify the reasoning skills that each specific production rule is designed to elicit. To impart a notion of how these "production rules" operate, and the kinds of reasoning skills targeted, the following rules, designating teacher behaviors, are taken from Collins (1977). We have selected those that have particular instructional implications for passive LD learners.

Rule 1: Ask about a known case. Essentially, the teacher instigates this rule to activate students' relevant prior knowledge. For example, prior to introducing a unit on, say, the growth of sugar cane, the teacher may ask the student whether he/she has eaten raw sugar cane before, or whether he/she knows sugar can be extracted from plants other than sugar beets.

Rule 5: Form a general rule for an insufficient factor. The teacher invokes this rule when the student proffers answers that indicate insufficient consideration of all the factors involved in the growth of, say, sugar cane. For example, if the student says that heat is the factor governing growth of sugar cane, the teacher may counter by asking if one can grow sugar cane in any place that is hot.

Rule 6: Pick a counter example for an insufficient factor. If a student fixates on one factor such as heat as the sole determinant of growth of sugar cane, the teacher uses this rule to highlight the insufficiency of the student's answer. For example, the teacher may say: "Do they grow sugar cane in the Sahara Desert?"

Rule 15: Request a test of the hypothesis about a factor. If the student says that both heat and water are 
necessary for growth of sugar cane, the teacher can ask him/her how he/she can go about checking the correctness of that notion.

Rule 17: Ask what the relevant factors to consider are. If the student fails to predict whether sugar cane can be grown in Southern China, the teacher calls upon this rule by asking the student to go through in his/her mind the necessary factors governing growth of sugar cane.

Rule 18: Question a prediction made without enough information. This rule should be invoked to curb students' tendency to talk before they think.

Rule 20: Point out an inconsistent prediction. Often, students are impatient in new learning situations. For example, after the teacher discusses the importance of heat in growing sugar cane, the student immediately says it should be found in the Sahara. The teacher then may ask how that can be possible since growing sugar cane requires much water. In using this rule, the teacher aims to make the student attend to and understand the interdependence between the two factors of heat and water in growing sugar cane.

The above are selected cases of Collins' (1977) "production rules" in the context of dialogues he held with individual students, in which he guided them in deriving the causal dependencies involved in rice growing. Clearly, the individualized and interactive process of learning promotes sound reasoning, more refined thinking skills in hypothesis generation, self-checking the consistency of one's reasoning and comprehensiveness of use of given data to make predictions, and the asking of relevant questions.

The generally passive learning style of LD adolescents and their need to learn various ways of effective thinking and studying make them potentially good candidates for Socratic tutoring. To try out Collins' Socratic tutoring technique to teach LD adolescents content knowledge in geography would be instructive. I suspect the use of Socratic tutoring will enable them to learn geography in a much more analytical way, which will not only increase their comprehension and retention of content but will also increase their motivation to learn the content.

\section{General Science}

\section{Instructional Sequence}

One of the most frustrating instructional issues confronting science teachers appears to be that of optimal instructional sequence. This question is acutely manifest in teaching formulas. Should we present the formula after a gradual build-up through concrete and familiar concepts and examples, or should we first present the formal formula? Which instructional sequence will provide optimal instruction in the sense that students not only acquire the concept and retain the technical details of the formula sufficiently, but that they also will demonstrate future transfer?

Mayer (1984) and his associates found that instructional sequences affect not only how much college students learn, but also the quality' of what they learn. Reflecting on his own programmatic research on this issue of instructional sequence, Mayer summarized how he derived that conclusion. Focusing on the concept of binomial probability, Mayer and his associates used two instructional methods with two different groups of college students. In the "formula group," instruction started with the students receiving the abstract formula, followed by an explanation of how to use it. In the "general method group," instruction began with familiar, concrete background knowledge, such as a discussion of what constitutes a trial and an outcome, with explanatory examples drawn from familiar notions of probability of rain, batting averages, and so forth. Only when the college students fully understood the underlying concepts of the formula did instruction continue to build up to the abstract formula.

Mayer and his associates comprehensively assessed the differential instructional effects on the two groups. On the posttest with items that were similar to the given examples, the "formula group" surpassed the "general method group." On the posttest with items on unusual problems and on recognizing when the formula applied or not, however, the "general method group" surpassed the "formula group." In short, the "general method group" showed more transfer while the "formula group" showed more retention of technical details.

Since LD adolescents need both to retain sufficient details and to transfer what they learn, a permissible extrapolation from the work of Mayer on when or how to sequence the instruction of a science formula appears to be to first teach LD adolescents the concepts and variables underlying the formula, using familiar concepts, and then build up to formal introduction of the formula with explanatory examples of its application.

\section{Use of Concrete Analogies}

Concrete analogies have played a useful role in the instruction of unfamiliar or technical science texts. Essentially these concrete analogies serve as advance organizers that provide an assimilative context to which new information can be systematically integrated (Mayer, 1984). For concrete analogies to be effective, 


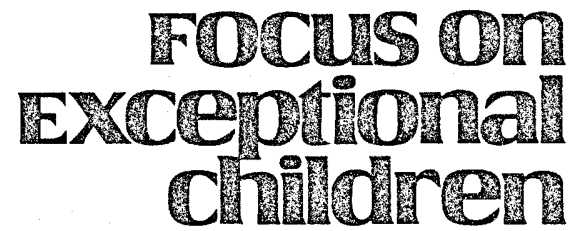

however, they must correspond closely with the properties or features of the subject matter they are supposed to mirror. Learners must be shown how elements in the concrete analogy map onto elements in the new information to be learned. The implications are that relevant analogies require careful construction.

Mayer has suggested four useful pointers for constructing analogies. First, "the analogy should allow one to generate all or some of the logical relationships in the to-be-learned material. Second, the analogy should provide a means of relating each unfamiliar element to each element in the analogical model. Third, the analogy should be easy to learn and remember. Fourth, the analogy will be useful if the learner would not normally think of using it or an equally useful one" (p. 231). Because most secondary students find learning new, abstract concepts in the knowledge domain of physics and other sciences difficult, careful construction of relevant analogies should greatly facilitate their formula learning.

Important instructional implications are inherent for teaching LD adolescents from Mayer's suggested instructional sequence - in teaching students science formulas and the use of concrete analogies to teach unfamiliar scientific concepts or text materials. Because LD students are inactive learners (Torgesen, 1977) and tend not to access spontaneously relevant background information, teachers must spend time mobilizing them to search for relevant background information so as to understand the new materials, before launching into instruction of a new abstract formula.

Equally important, because they are inactive learners, LD students should not learn any formula by rote. To ensure that LD students learn any scientific formula with understanding, teachers should attempt the instructional sequence derived empirically by Mayer (1984) and described above. Similarly, the use of concrete analogy in teaching LD adolescents unfamiliar science concepts or text appears to be particularly appropriate because of their deficient repertoire of abstract verbal concepts.

\section{EPILOGUE}

This article has focused on ways of enhancing LD adolescents' acquisition of content knowledge in social studies, geography, and general science. Quite a number of potentially useful instructional techniques appear to be ready for a try-out with LD adolescents. Their use awaits the committed teacher and researcher interested in intervention research. Until we try these various instructional techniques systematically and thoughtfully, we will not have a solid basis for reflecting on the extent of their usefulness.

\section{REFERENCES}

Alley, G., \& Deshler, D. (1979). Teaching the learning disabled adolescent: Strategies and methods. Denver: Love Publishing Co.

Armbruster, B.B., \& Anderson, T.H. (1980). The effect of mapping on the free recall of expository text (Tech. Rep. No. 160). UrbanaChampaign: University of Illinois.

Aulls, M.W. (1978). Developmental and remedial reading in the middle grades. Boston: Allyn \& Bacon.

Brown, A.L., Campione, J.C., \& Day, J.D. (1981). Learning to learn: On training students to learn from texts. Educational Researcher, 10 , 14-21.

Brown, A.L., \& Day, J.D. (1983). Macrorules for summarizing texts: The development of expertise (Tech. Rep. No. 270). UrbanaChampaign: University of Illinois.

Brown, A.L., Day, J.D., \& Jones, R.S. (in press). The development of plans for summarizing texts. Child Development.

Chi, M.T.H. (1981). Interactive roles of knowledge and strategies in development. In S. Chipman, J. Segal, \& R. Glaser (Eds.)', Thinking and learning skills: Current research and open questions (Vol. 2). Hillsdale, NJ: Erlbaum.

Collins, A. (1977). Processes in acquiring knowledge. In R.C. Anderson, R.J. Spiro, \& W.E. Montague (Eds.). Schooling and the acquisition of knowledge (pp. 339-361). Hillsdale, NJ: Erlbaum.

Graham, S. (1983). The effect of self-instructional procedures on LD students' handwriting performance. Learning Disability Quarterly, $6,231-234$.

Hare, V.C., \& Borchardt, K.M. (1983). Direct instruction of summarization skills. Unpublished manuscript, University of Illinois, Chicago.

Kintsch, W., \& van Dijk, T.A. (1978). Toward a model of text comprehension and production. Psychological Review, 85, 363-394.

Loper, A.B., Hallahan, D.P., \& Ianna, S.O. (1982). Meta-attention in learning-disabled and normal students. Learning Disability' Quarterly, 5, 29-36.

Mayer, R.E. (1984). What have we learned about increasing the meaningfulness of science prose? Science Education, 67, 223-237.

Miyake, N., \& Norman, D.A. (1978). To ask a question, one must know enough to know what is not known. Journal of Verbal Learning and Verbal Behavior, 18, 357-364.

Palincsar, A.S. (1982). Improving the reading comprehension of junior high students through reciprocal teaching of comprehensionmonitoring strategies. Unpublished doctoral dissertation, University of Illinois, Urbana-Champaign.

Slater, W.H., Graves, M.F., \& Piche, G.L. (1984, April). The effects of structural organizers on ninth grade students' comprehension and recall of four patterns of expository text. Paper presented at the American Educational Research Association convention, New Orleans.

Taylor, B.M. (1982). Text structure and children's comprehension and memory for expository material. Journal of Educational Psy'chologl. 74(3), 323-340.

Torgeson, J.K. (1977). The role of nonspecific factors in the task performance of learning-disabled children: A theoretical assessment. Journal of Learning Disabilities, 10, 27-34.

Voss, J.F. (1982, March). Know'ledge and social science problem solving. Paper presented at AERA meeting, New York City.

Wong, B.Y.L. (1984). Metacognition and learning disabilities. In T.G. Waller, D. Forrest-Pressley, \& E. MacKinnon (Eds.), Metacognition, cognition and human performance. New York: Academic Press.

Wong, B.Y.L., \& Jones, W. (1982). Increasing metacomprehension in learning-disabled and normally-achieving students through selfquestioning training. Learning Disability Quarterly, 5, 228-240. 